\title{
Botulinum Toxin Therapy in Dysthyroid Strabismus
}

\author{
C. J. LYONS, S. F. VICKERS, J. P. LEE \\ London
}

\begin{abstract}
Summary
We report our experience with the use of Botulinum toxin injection in 38 patients (64 injections) with severe dysthyroid strabismus. Three quarters of the injections led to a decrease in the angle of the squint by a mean $75 \%$ of the initial deviation. The average duration of effect was two months. Twenty six patients went on to surgery after stabilisation of their squint and endocrine status. Six patients achieved a stable longterm result with Botulinum toxin only. We suggest these results of treatment of early dysthyroid myopathy are more consistent with the characteristics of inflammatory spasm than contracture. The value of Botulinum toxin as a temporary means of maintaining binocularity in these young patients is discussed.
\end{abstract}

Dysthyroid eye disease is one of the most disabling non-malignant ocular conditions. In addition to its disfiguring effect, the patient is also at risk of visual loss from corneal exposure or optic nerve compression. Dysthyroid strabismus can also be disabling, particularly when it results in intolerable diplopia which can only be relieved by occlusion of one eye; Patients will frequently resort to this expedient once other alternatives such as the adoption of a gross compensatory head posture or the use of high-powered prisms (which degrade the quality of the image) become impractical.

Although surgery is effective in relieving restriction, it cannot be performed until stability both of endocrine status and muscle balance has been achieved; We have used Botulinum Neurotoxin A injections to treat such patients.

The technique of intramuscular injection of Botulinum toxin under EMG control was introduced by Alan Scott in 1979..$^{1,2,3}$ This treatment, the first new approach to the therapy of strabismus since Dieffenbach's introduction of surgery 150 years ago, has been adopted with enthusiasm by many clinics around the world.

Recognised applications include sixth nerve palsy ${ }^{4,5}$ surgical overcorrections ${ }^{6}$ and consecutive exotropia. ${ }^{7}$ In addition, a role in infantile strabismus has been suggested. ${ }^{8,9}$ Our preliminary results of treatment of dysthyroid ophthalmopathy with Botulinum toxin were presented in $1985^{10}$ and we now present our results up to December 1988.

\section{Materials and methods:}

From July 1984 to December 1988, 38 consecutive patients with strabismus due to dysthyroid disease were treated in the Botulinum Toxin Clinic at Moorfields Eye Hospital. There were 23 females and 15 males. Their age ranged from 32 to 72 years with a mean of 56 years.

At the time of 'treatment, seven patients were taking carbimazole, one propylthiouracil and one oral steroids. Two patients had received radio-iodine treatment in the previous month.

Three patients had previously undergone 
bilateral orbital decompression, and six strabismus surgery.

The initial mean deviation for hypotropia was 23.3 prism dioptres (PD) (median $=22$, range 4-60) and for esotropia was $27.8 \mathrm{PD}$ (median $=20$, range 14-45).

The injection technique is essentially that described by JPL in previous papers, i.e. the administration of 62.5 picogrammes of Botulinum neurotoxin $\mathrm{A}$ in $0.1 \mathrm{ml}$ of normal saline under EMG control. The inferior rectus is injected through the lower lid as access is difficult via the lower conjunctival fornix. The use of an oscilloscope in addition to an audible signal improves muscle localisation. This is particularly helpful when injecting the inferior rectus, whose EMG signal in dysthyroid disease is of lower amplitude than that of the horizontal recti.

In this series, 32 inferior, five medial and one lateral recti were injected. Each patient received at least one projection while 27 went on to a second. Two only received a third injection.

Sixty-four injections were fully documented; Of these, three quarters resulted in a decrease in the angle of the squint. In the others, the effect of the injection was minimal or absent.

For injections which were effective, the mean change in angle was 14 Prism Diopters or $75 \%$ of the initial deviation. In nine of this group, there was a temporary over-correction of the deviation; five hypotropic eyes became hypertropic and four esotropic eyes became exotropic. This result was proportionally much more common in medial rectus injections.

The fields of BSV were scored pre- and post-injection by the method described by Woodruff ${ }^{11}$ for 16 injections. In eight of these, there was no field of BSV prior to the injection. At one week post-injection, the mean BSV score for this group was $50 \%$ (range $=5$ $87 \%$ ). In four cases, there was a mean of $27 \%$ improvement following the injection. In two cases, there was no change from pre- to postinjection scores while in two cases, the score worsened from $56 \%$ to $2 \%$, and $65 \%$ to $42 \%$ following over-correction. These measurements however only reflect the position one week following the injection; in patients whose deviation was overcorrected, one would expect an improvement of the BSV score as the effect of the toxin wore off, prior to recurrence of the original deviation.

In the majority of patients, the effect of toxin was undetectable clinically after two months. Complications were limited to one case of partial ptosis.

\section{Outcome:}

Follow-up ranged from four months to 4.7 years.

In the long term, 26 of the 38 patients underwent strabismus surgery. Considering this group first:

In 12 of these 26 , Botulinum toxin was found to be of little use due to insufficient reduction in the angle of the deviation. In the remaining 14 , the effect of toxin was beneficial but they chose to stop this treatment for a variety of reasons ranging from moving away from this area, to a dislike of the actual technique. Also, patients were advised to have surgery if it was felt that although toxin had a useful effect, it was short-lived and the underlying angle had stabilised.

Twelve patients did NOT go on to surgery. Of these: Six declined further treatment by this method and either returned to management with prisms or were lost to follow up.

Six others achieved a stable long-term result.

By long-term, we mean a stable result one year at least after the last botulinum injection, in which the patient has comfortable binocular single vision both in primary and reading positions. It is worth studying this group in detail:

(1) The first was a 56 year-old man whose compensatory head posture made driving difficult. His left inferior rectus was injected and the hypotropia was reduced to two prism dioptres. This was maintained as a result of the development of symmetrical inferior rectus involvement by his dysthyroid disease. (Follow-up $(\mathrm{FU})=4$ years)

(2) A 60 year-old female who had previously undergone strabismus surgery was left with a 16 dioptre right hypotropia. She responded well to two injections of toxin to her inferior rectus and has retained BSV with a four dioptre prism. ( $F U=4$ years) 
(3) A 64 year-old male patient's 14 PD residual esotropia was converted to a small exophoria by a toxin injection to the medial rectus. The esotropia did not recur. (FU=8 months)

(4) A 65 year-old female patient's six dioptre right hypotropia was converted to a two dioptre left hyperphoria by two injections to the left inferior rectus. A stable and welltolerated two dioptre right right hyperphoria has since recurred. ( $F U=1$ year)

(5) A 59 year-old female was referred with a very marked compensatory head posture due to a 27 PD right hypotropia. She responded well to her second injection and the deviation has remained stable at 12 prism dioptres. She compensates for this with a small head posture.

(6) A 67 year-old male had two previous squint operations which left him with a 24 PD left hypotropia. This angle was reduced to zero by one injection. Although he found the diplopia in downgaze from his paralysed inferior rectus very disturbing at first, his field of BSV soon improved and he is now free of diplopia both in primary position and in downgaze.

This group is worthy of further comment; One patient's long-term success can be attributed to the development of symmetrical inferior rectus involvement which freed him from diplopia. Secondly, three of these six patients had previously undergone unsuccessful surgery. To express this another way, half of all the patients who had previously undergone surgery achieved a satisfactory longterm result with toxin only. Also, it is apparent that in most of these cases long-term control is not a result of a prolonged paralysis but rather that, having recovered BSV through the effect of toxin, they manage to control their steadily recurrent phoria. Lastly, patients who achieved long-term control with botulinum toxin are older than the average of our 38 patients $(\mathrm{p}<0.05)$.

\section{Discussion}

We have demonstrated that Botulinum toxin will cause its typical effect of flaccid paralysis and change in deviation even in dysthyroid muscles. This is initially surprising as one tends to associate this disease process with fibrotic inelastic muscles which tether and restrict globe rotations.

However this appearance is usually seen at surgery, which tends to be undertaken only at the end of the disease process when the inflammation is 'burned out'. Many of our patients were treated early in the disease, one quarter being still on anti-thyroid medication.

These results suggest that at least early in the disease the process is partially reversible; the term 'contracture' is inappropriate and a better term in this context would be 'inflammatory spasm'.

The length-tension characteristics of dysthyroid muscles tend to confirm this finding; Simmonsz and Kommerell ${ }^{12}$ have postulated that there could be replacement of normal muscle fibres by faster fibre types in dysthyroid eye disease. These fibres would contract powerfully under the continuous 'baseline' innervation of extra-ocular muscles. Inhibition of firing by Hering's law (or by Botulinum toxin) would, in this situation, lead to con-
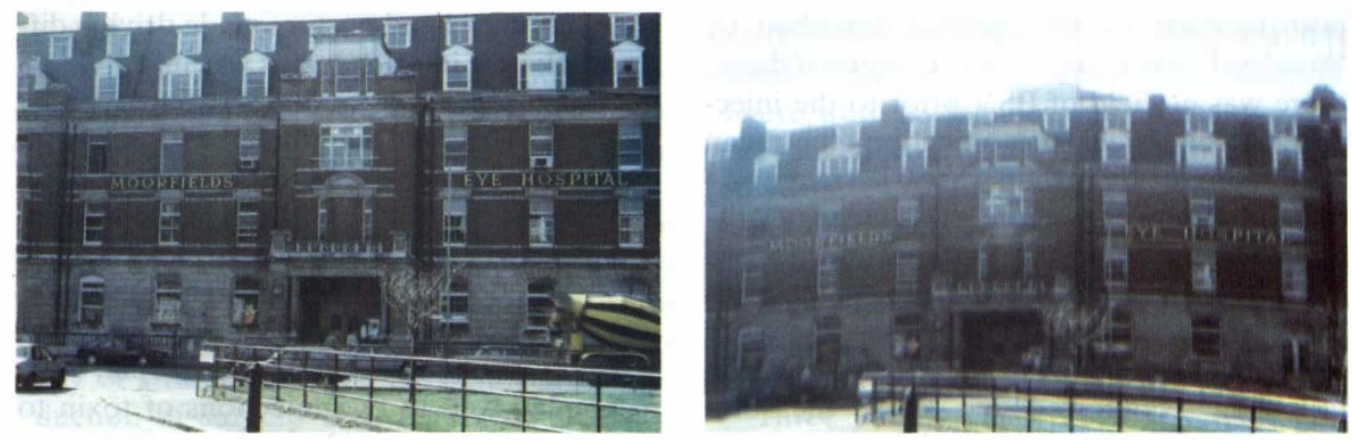

Fig. 1. The right-hand photograph was taken through a 30 PD Fresnel prism to illustrate the degradation in the quality of the image which results from the use of this device. 
Table I Summarises the characteristics of the group under study, and the outcome of the treatment

\begin{tabular}{|c|c|}
\hline Patients: & $38(23 \mathrm{~F}, 15 \mathrm{M})$ \\
\hline Age range: & $32-72 y(m=56 y)$ \\
\hline Antithyroid medication at time of BXTA: & 11 patients $(29 \%)$ \\
\hline Previous orbital decompression: & $3(8 \%)$ \\
\hline Previous strabismus surgery: & $6(16 \%)$ \\
\hline \multicolumn{2}{|l|}{ Mean pre-injection deviation: } \\
\hline Hypotropia: & 23.3 PD \\
\hline Esotropia: & 27.8 PD \\
\hline \multicolumn{2}{|l|}{ Muscles injected: } \\
\hline Inferior rectus: & 32 \\
\hline Medial rectus: & 5 \\
\hline Lateral rectus: & 1 \\
\hline \multicolumn{2}{|l|}{ Of 64 injections: } \\
\hline$<10 \%$ angle reduction (no effect): & $16(25 \%)$ \\
\hline $\begin{array}{l}>10 \% \text { angle reduction (effective): } \\
\text { Of the } 48 \text { 'effective' injections: }\end{array}$ & $48(75 \%)$ \\
\hline Mean change in deviation: & $14 \mathrm{PD}$ or $75 \%$ of initial angle \\
\hline Follow-up: & 4 months to 4.7 years \\
\hline \multicolumn{2}{|l|}{ Outcome: } \\
\hline \multicolumn{2}{|l|}{ Strabismus surgery: 26 of 38 patients } \\
\hline 12 of $26:$ & BTXA little effect \\
\hline 14 of $26:$ & Angle stable, moved away, not keen on injections \\
\hline \multicolumn{2}{|l|}{ No strabismus surgery: 12 of 38 patients } \\
\hline 6 of $12:$ & declined further treatment \\
\hline 6 of 12: & long-term result \\
\hline Duration of effect: & 2 months (except 6 long-term) \\
\hline Complications: & \\
\hline Reversible partial ptosis: & 1 patient \\
\hline
\end{tabular}

siderable relaxation unless fibrosis had already occurred.

In this series, five out of six patients referred for toxin treatment eventually underwent a surgical squint correction. Why then, use toxin therapy at all?

It is well known that surgery has to be delayed in active disease where the deviation is not stable. During this period, patients are left with three alternatives: occlusion of one eye, Fresnel prisms or toxin.

These patients are young; $84 \%$ of this series were under the age of retirement from work. They may well need binocular function and relative freedom from diplopia to keep their jobs especially if these involve driving or reading.

Occlusion is cosmetically unsatisfactory and causes loss of stereopsis and of visual field.

Low power Fresnel prisms are useful in maintaining binocularity. However they are of limited use in the large deviations of dysthyroid disease because the image they produce is markedly degraded (Fig. 1) resulting in decreased acuity. Furthermore, they are of little value in very incomitant deviations.

Botulinum toxin may allow the patient to remain binocular during the acute part of the disease with definitive surgery when stabilisation of signs occurs. In addition, toxin is especially useful in the management of small surgical over- or under-correction.

Finally we find that in one sixth of our patients long-term stability will occur, obviating the need for surgery.

We know of no comparable study of Botulinum tocxin therapy in dysthyroid strabismus. Scott, ${ }^{13}$ and Dunn et al.,${ }^{14}$ have reported small series with short follow-up, in which no definitive trend to improvement was detectable. We feel that there is a place for the use of this technique in the management of acute dysthyroid strabismus. It is relatively atraumatic, quick, effective and reversible, and may allow relatively young patients to avoid long-term uniocular occlusion.

\footnotetext{
References

${ }^{1}$ Scott AB, Rosenbaum AL, Collins CC: Pharmac-
} 
ologic weakening of extraocular muscles. Invest Ophthalmol 1973, 12: 924-7.

${ }^{2}$ Scott AB: Botulinum Toxin injection into extraocular muscles as an alternative to strabismus surgery. Ophthalmology 1980, 87: 1044-9.

${ }^{3}$ Scott AB: Botulinum toxin injection of eye muscles to correct strabismus. Trans Am Ophthalmol Soc 1981, Vol LXXIX: 734-70.

${ }^{4}$ Fitzsimmons R, Lee JP, Elston JS: Treatment of sixth nerve palsy in adults with combined botulinum toxin chemodenervation and surgery. Ophthalmology 1988, 95: 1535-42.

${ }^{5}$ Fitzsimmons R, Lee JP, Elston JS: The role of Botulinum Toxin in the management of sixth nerve palsy. Eye 1989, 3: 391-400.

${ }^{6}$ Biglan AW, Burenstine RA, Rogers GL, Saunders RA: Management of strabismus with Botulinum toxin. Ophthalmology 1989, 96: 935-43.

${ }^{7}$ Lee JP, Elston JS, Vickers S, Powell C, Ketley J, Hogg C: Botulinum toxin therapy for squint. Eye 1988, 2: 24-8.

${ }^{8}$ Magoon EM: Botulinum toxin chemodenervation for strabismus in infants and children. J Ped Ophthalmol \& Strab 1984, 21 (3): 110-13.
${ }^{9}$ Magoon EH and Scott AB: Botulinum toxin chemodenervation in infants and children: an alternative to incisional strabismus surgery. J Paediatr 1987 , 110 (5): 719-22.

${ }^{10}$ Lee JP and Elston JS: Treatment of acute dysthyroid ophthalmopathy with botulinum toxin injections. Proceedings of XVth meeting of the European Strabismological Assoc. Lausanne, 1985. Ed Deller \& Weiss. p. 153.

${ }^{11}$ Woodruff G, O'Reilly C, Kraft S: Functional scoring of the field of Binocular Single Vision in patients with diplopia. Ophthalmology 1987, 94: 1554-61.

${ }^{12}$ Simmonsz HJ and Kommerell G: In Graves' disease, increased muscle tension and reduced elasticity of affected muscles is primarily caused by active muscle contraction. Neuro-ophthalmol 1989, 9: 243-5.

${ }^{13}$ Scott AB: Injection treatment of endocrine orbital myopathy. Doc Ophthalmol 1984, 58: 141-5.

${ }^{14}$ Dunn WJ, Arnold AC, O'Connor PS: Botulinum toxin for the treatment of Dysthyroid Ocular Myopathy. Ophthalmology 1986, 93: 470-5. 